\title{
28 Research Square \\ Load Balancing in DCN Servers through SDN Machine Learning Algorithm
}

Sulthana Begam ( $\square$ sulthanamshafiphd@gmail.com )

Aalim Muhammed Salegh College of Engineering

\section{Sangeetha M}

Coimbatore Institute of Technology

Shanker N R

Aalim Muhammed Salegh College of Engineering

\section{Research Article}

Keywords: Data Center Networks (DCN), Software Defined Networking (SDN), Load Balancing, Regression model, Server selection, Open Flow.

Posted Date: March 11th, 2021

DOl: https://doi.org/10.21203/rs.3.rs-277161/v1

License: (c) (1) This work is licensed under a Creative Commons Attribution 4.0 International License.

Read Full License

Version of Record: A version of this preprint was published at Arabian Journal for Science and Engineering on July 10th, 2021. See the published version at https://doi.org/10.1007/s13369-021-059111. 


\section{Abstract}

Software Defined Networking (SDN) manages data traffic in Data Center Network (DCN). SDN improves utilization of large scale network resource and performance of network application. In SDN, load balancing technique optimizes the data flow during transmission through server load deviation after evaluating the network status dynamically. However, load deviation in the network needs optimum server selection and routing path with respect to less time and complexity. In this paper, we propose a M ultiple $\mathrm{R}$ egression $\mathrm{B}$ ased S earching (MRBS) algorithm for optimum server selection and routing path in DCN. The appropriate server selection during heavy load conditions such as message spikes, different message frequencies and unpredictable traffic patterns are done through regression based analysis and correlation of various server parameters, only after detecting the types of traffic and loads based on bandwidth. The parameters included in the regression modeling are load, response time, bandwidth and server utilization. Moreover, the heuristic algorithm is combined with regression model for efficient path selection. The proposed algorithm reduces the delay and time more than $85 \%$ when compared with traditional algorithms due to stochastic gradient decent weights estimation.

\section{Full Text}

Due to technical limitations, full-text HTML conversion of this manuscript could not be completed. However, the latest manuscript can be downloaded and accessed as a PDF.

\section{Figures}

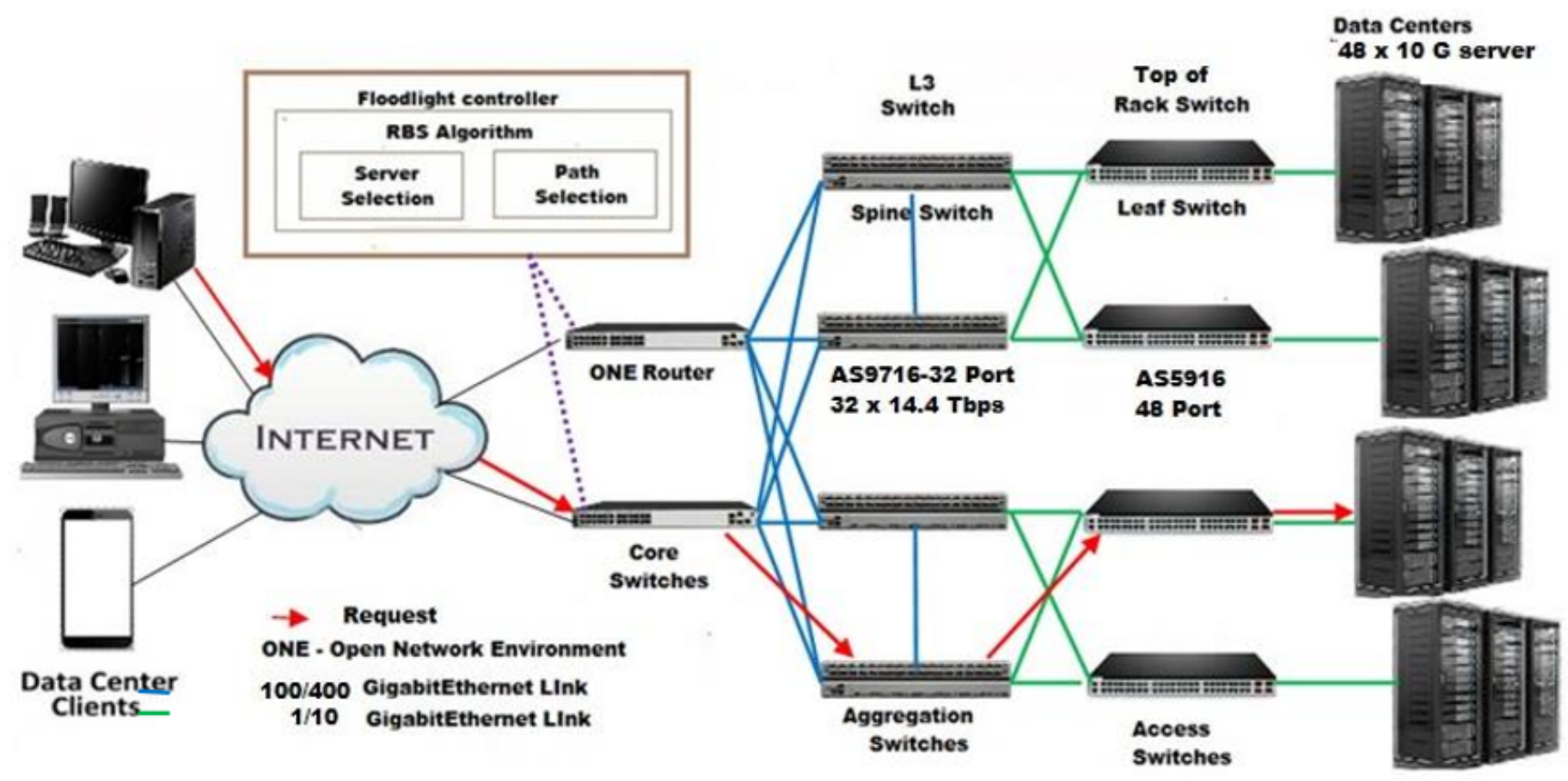

Figure 1 
Block diagram of MRBS algorithm implemented in Spine-Leaf architecture of DCN

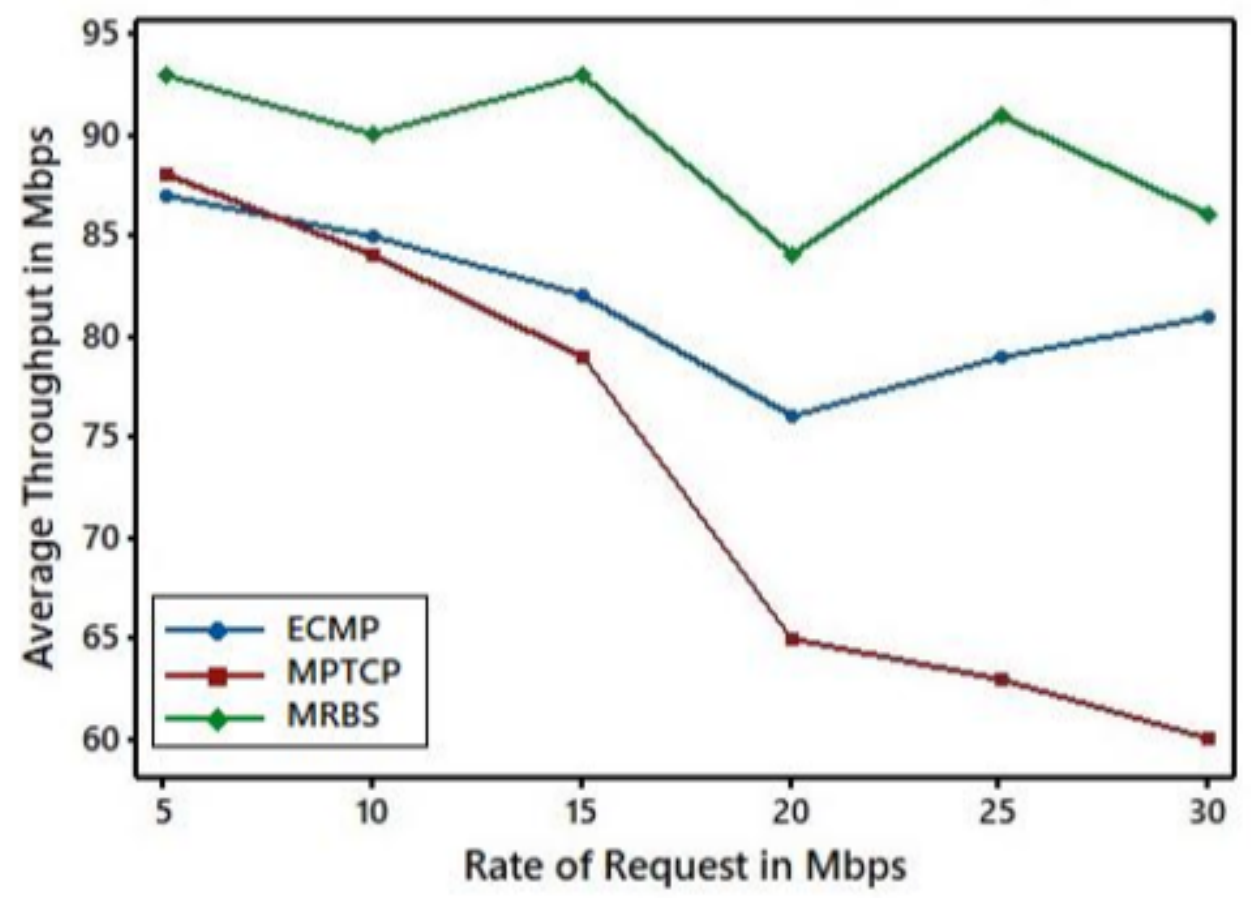

Figure 2

Average throughput of servers in different rate of request and time

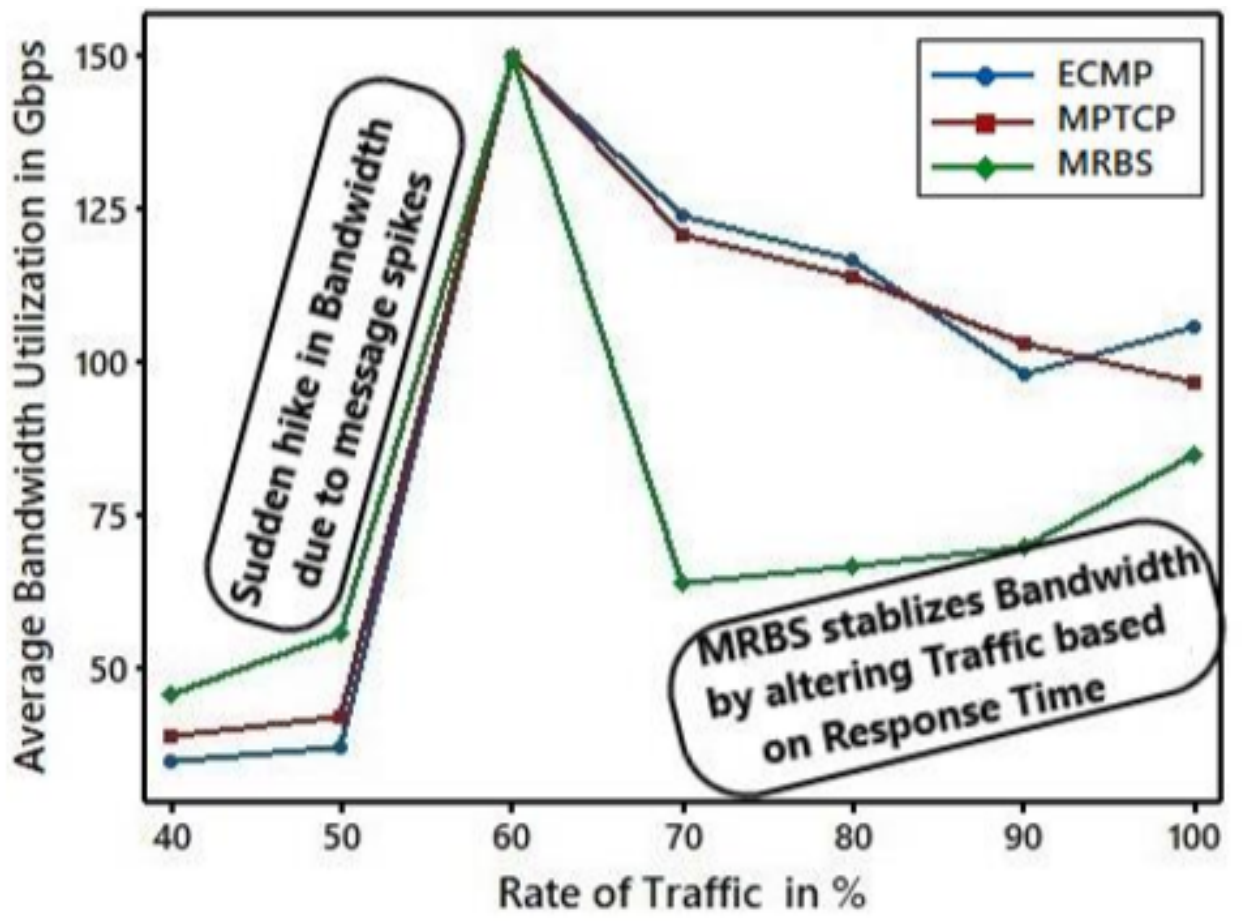

Figure 3

Average bandwidth Utilization of DCN Networks with sudden message spikes generated by iperf 


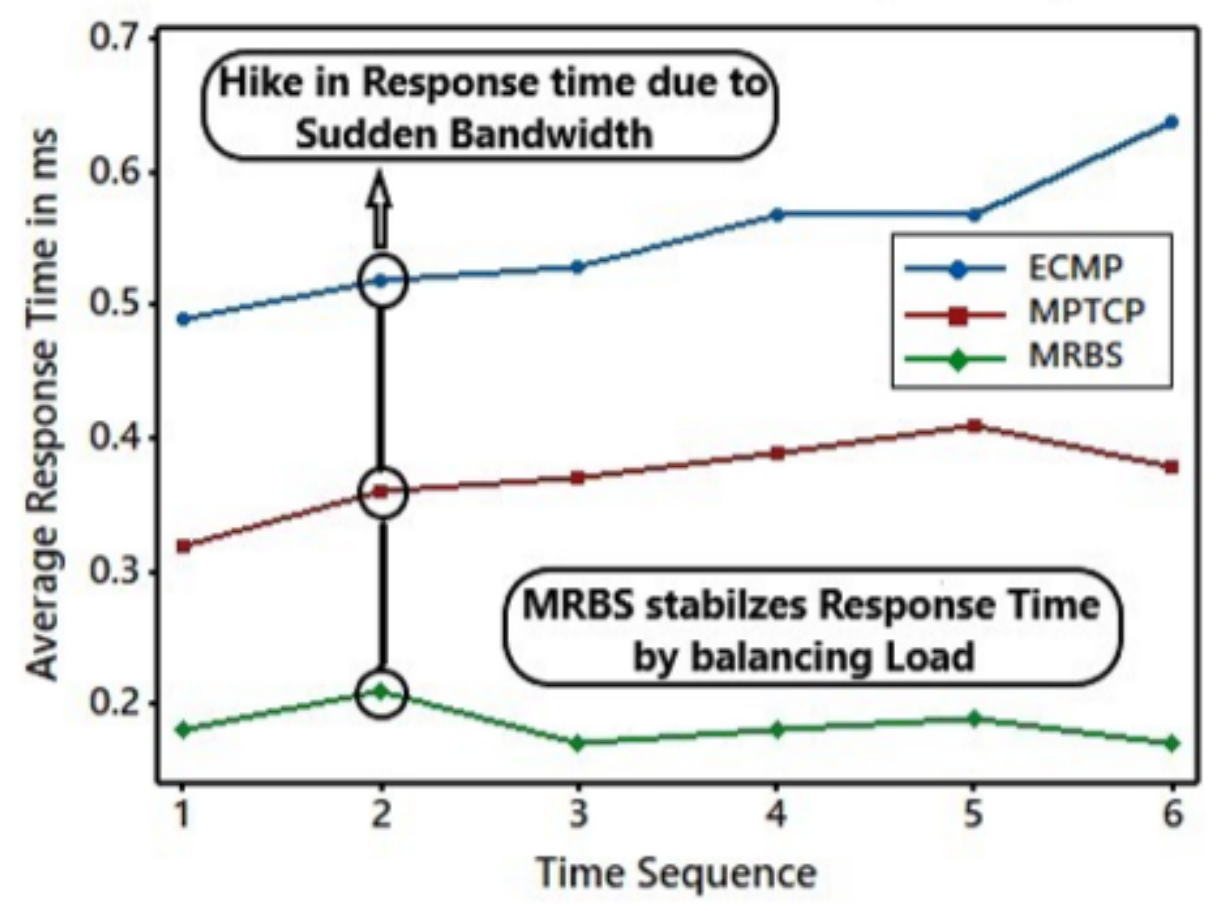

Figure 4

Average Response Time of Controller in $10 \mathrm{~g}$ Server

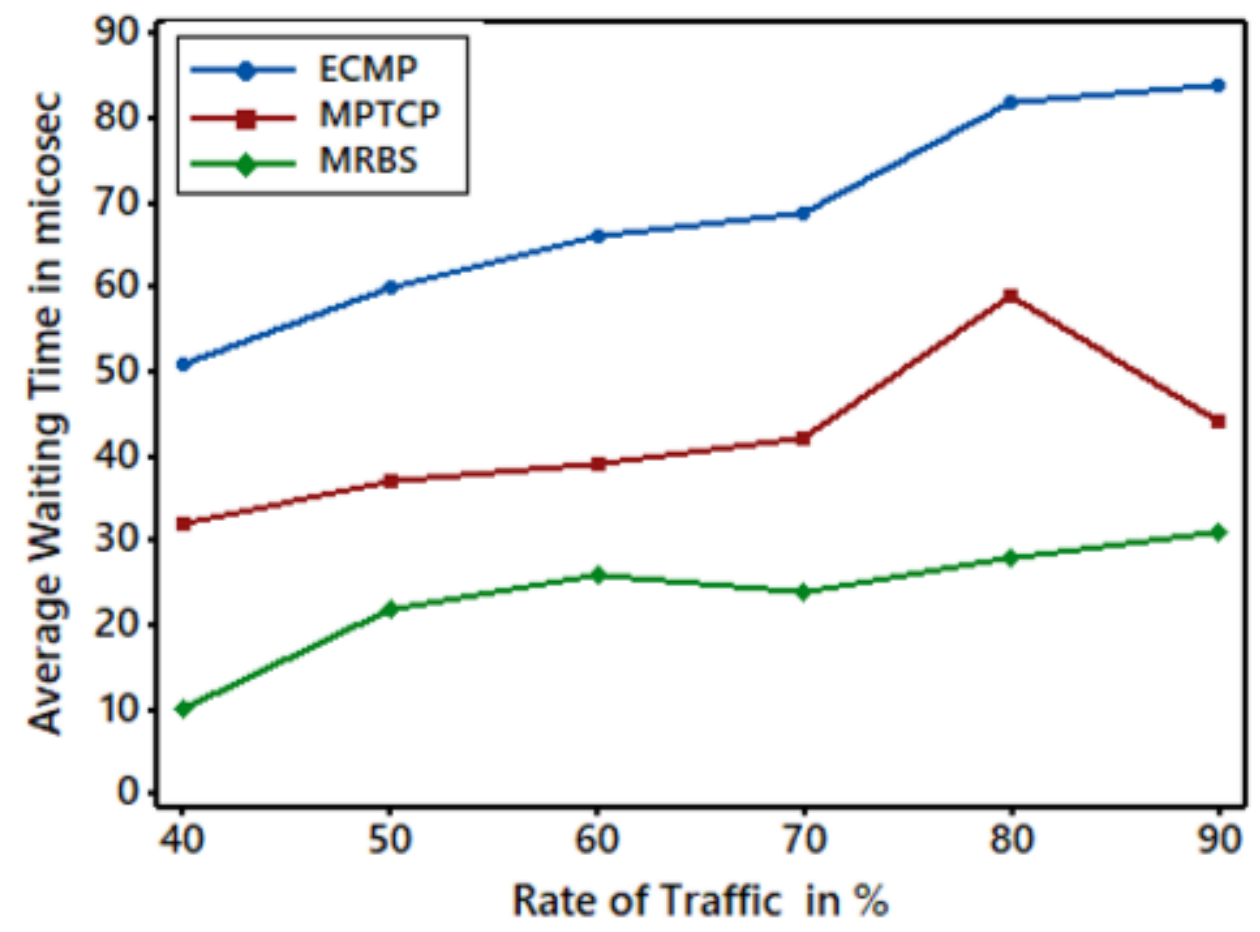

Figure 5

Average Delay of Controller during Web traffic 


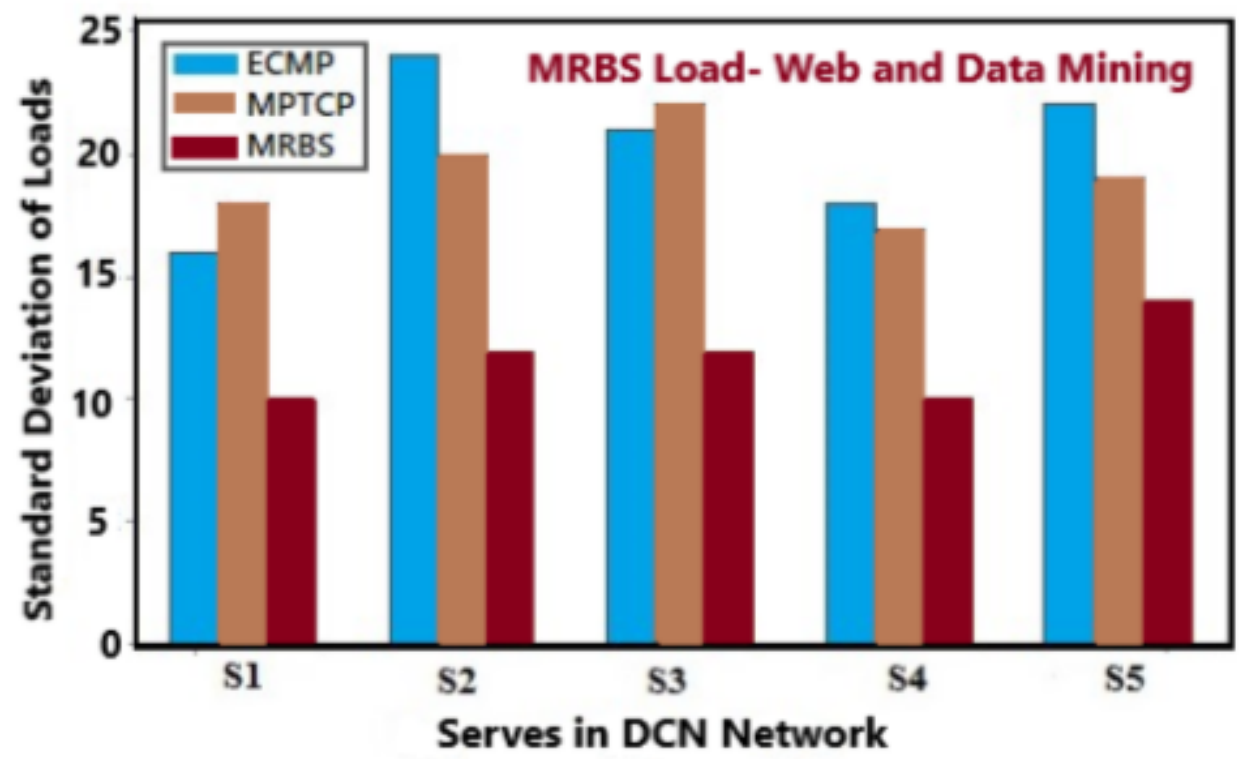

Figure 6

Standard deviation of Loads of $10 \mathrm{~g}$ Servers due to data mining traffic

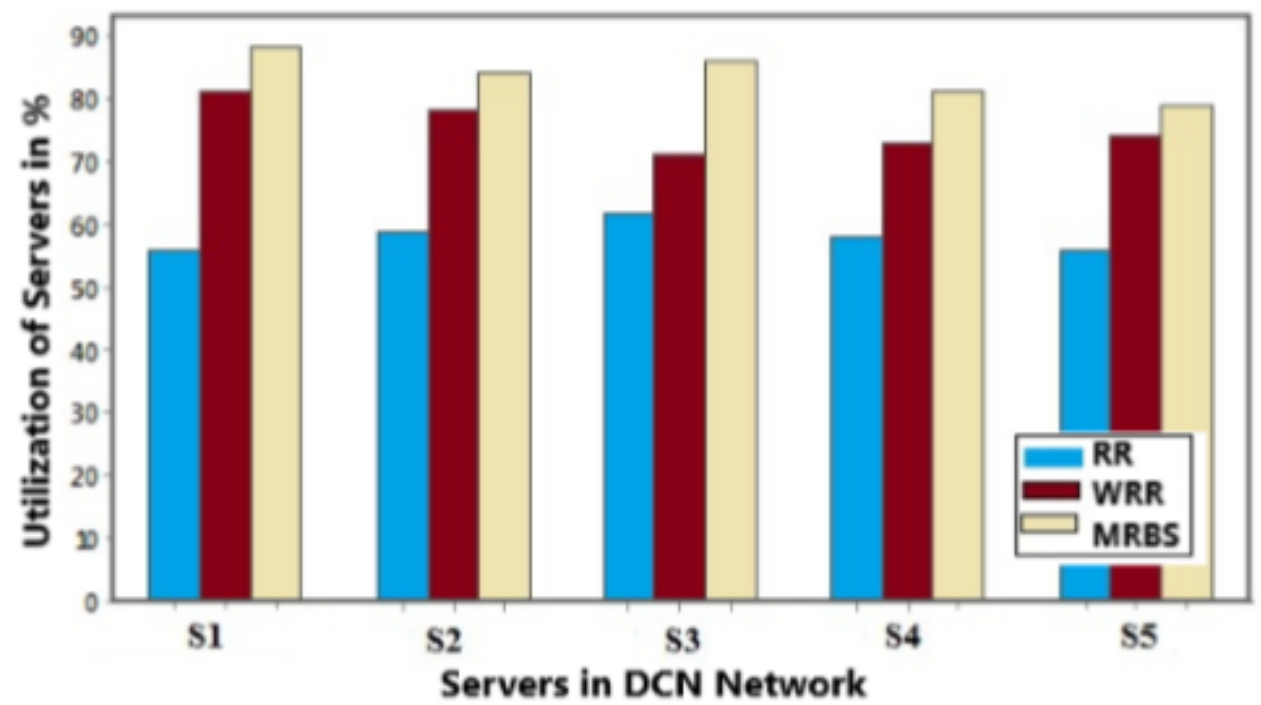

Figure 7

Average $10 \mathrm{~g}$ server utilization of Scheduling Techniques 